\title{
Geographic distribution of the incidence of colorectal cancer in Iran: a population-based study
}

\author{
Fatemeh Khosravi Shadmani', Erfan Ayubi i, , Salman Khazaei ${ }^{4}$, Mohadeseh Sani ${ }^{5}$, \\ Shiva Mansouri Hanis ${ }^{6}$, Somayeh Khazaei ${ }^{7}$, Mokhtar Soheylizad ${ }^{8}$, Kamyar Mansori ${ }^{9,10}$ \\ ${ }^{1}$ Modeling in Health Research Center, Institute for Futures Studies in Health, Kerman University of Medical Sciences, Kerman, Iran; ${ }^{2}$ Department \\ of Epidemiology, School of Public Health, Shahid Beheshti University of Medical Sciences, Tehran, Iran; ${ }^{3}$ Department of Epidemiology and \\ Biostatistics, School of Public Health, Tehran University of Medical Sciences, Tehran, Iran; ${ }^{4}$ Department of Epidemiology, School of Public Health, \\ Hamadan University of Medical Sciences, Hamadan, Iran; ${ }^{5}$ School of Medicine, Zabol University of Medical Sciences, Zabol, Iran; ${ }^{6}$ School of \\ Public Health, Dezful University of Medical Sciences, Dezful, Iran; ' Department of Para Medicine, Hamadan University of Medical Sciences, \\ Hamadan, Iran; ${ }^{8}$ Social Determinants in Health Promotion Research Center, Hormozgan University of Medical Sciences, Bandar Abbas, Iran; \\ ${ }^{9}$ Social Development and Health Promotion Research Center, Gonabad University of Medical Sciences, Gonabad, Iran; ${ }^{10}$ Department of \\ Epidemiology, School of Public Health, Iran University of Medical Sciences, Tehran, Iran
}

OBJECTIVES: Colorectal cancer (CRC) is the third most common cancer and the fourth most common cause of cancer death in the world. The aim of this study was to investigate the provincial distribution of the incidence of CRC across Iran.

METHODS: This epidemiologic study used data from the National Cancer Registry of Iran and the Center for Disease Control and Prevention of the Ministry of Health and Medical Education of Iran. The average annual age-standardized rate (ASR) for the incidence of CRC was calculated for each province.

RESULTS: We found that adenocarcinoma (not otherwise specified) was the most common histological subtype of CRC in males and females, accounting for 81.91 and $81.95 \%$ of CRC cases, respectively. Signet ring cell carcinoma was the least prevalent subtype of CRC in males and females and accounted for 1.5 and $0.94 \%$ of CRC cases, respectively. In patients aged 45 years or older, there was a steady upward trend in the incidence of CRC, and the highest ASR of CRC incidence among both males and females was in the age group of 80-84 years, with an ASR of 144.69 per 100,000 person-years for males and 119.18 per 100,000 person-years for females. The highest incidence rates of CRC in Iran were found in the central, northern, and western provinces. Provinces in the southeast of Iran had the lowest incidence rates of CRC.

CONCLUSIONS: Wide geographical variation was found in the incidence of CRC across the 31 provinces of Iran. These variations must be considered for prevention and control programs for CRC, as well as for resource allocation purposes.

KEY WORDS: Colorectal neoplasms, Sex, Incidence, Epidemiologic studies, Iran

\footnotetext{
Correspondence: Kamyar Mansori

Social Development and Health Promotion Research Center, Gonabad University of Medical Sciences, Asian Road, Gonabad 9691793718, Iran

E-mail: kamyarmansori@yahoo.com

Received: Oct 12, 2016 / Accepted: May 17, 2017 / Published: May 17, 2017

This article is available from: http://e-epih.org/

(C) This is an open-access article distributed under the terms of the Creative Commons Attribution License (http://creativecommons.org/licenses/by/4.0/), which permits unrestricted use, distribution, and reproduction in any medium provided the original work is properly cited.
}

(C) 2017, Korean Society of Epidemiology

\section{INTRODUCTION}

Colorectal cancer (CRC) is the third most common cancer in the world after lung cancer and breast cancer. It is also fourth most common cause of cancer death globally [1]. In males, CRC is the third most commonly diagnosed cancer worldwide, and in females, it is the second most commonly diagnosed cancer. In 2012, more than $9 \%$ of all new cases of cancer were attributed to CRC, accounting for roughly 1.4 million cases [2]. Of these cases, 746,000 were in males and 614,000 were in females [3]. 
The incidence of CRC is not distributed uniformly around the world, with the occurrence of CRC differing at least 25-fold from country to country [4]. A high incidence of CRC has been observed in high-income countries, such as the US, New Zealand, and Canada, and developing countries also continue to experience increasing incidence rates [5]. The highest increase in rates has been observed in Asian countries [6]. In Iran, where CRC is the fourth most common type of cancer (the third most common in females and the fifth most common in males), the incidence of the disease has experienced the same increase as those of other Asian countries, with CRC accounting for $8.4 \%$ of all cancers in the country [7]. One study found that the burden of CRC in Iran, based on the disability-adjusted life years index, was 52,53 years [8].

Inflammatory bowel disease, family history of CRC, obesity, diet, smoking, physical inactivity [9], and diabetes [10] are well-known risk factors for CRC. Furthermore, the incidence varies across different geographic areas due to environmental, social, and behavioral factors, with environmental risk factors having been found to play the most important role in the incidence and development of CRC [9]. Consequently, individuals within the same or adjacent areas that tend to share the same ethnic and cultural characteristics may be exposed to the same risk factors.

There are many ethnic groups in Iran that are subject to a variety of different risk factors. This study aimed to describe the geographic differences in the incidence of CRC across the country. Using these findings, we can provide policy makers and planners with advice on resource allocation, screening programs, and treatment strategies for various provinces across Iran.

\section{MATERIAL AND METHODS}

This epidemiologic study used data from 2008 that were collected at the provincial level from the National Cancer Registry of Iran

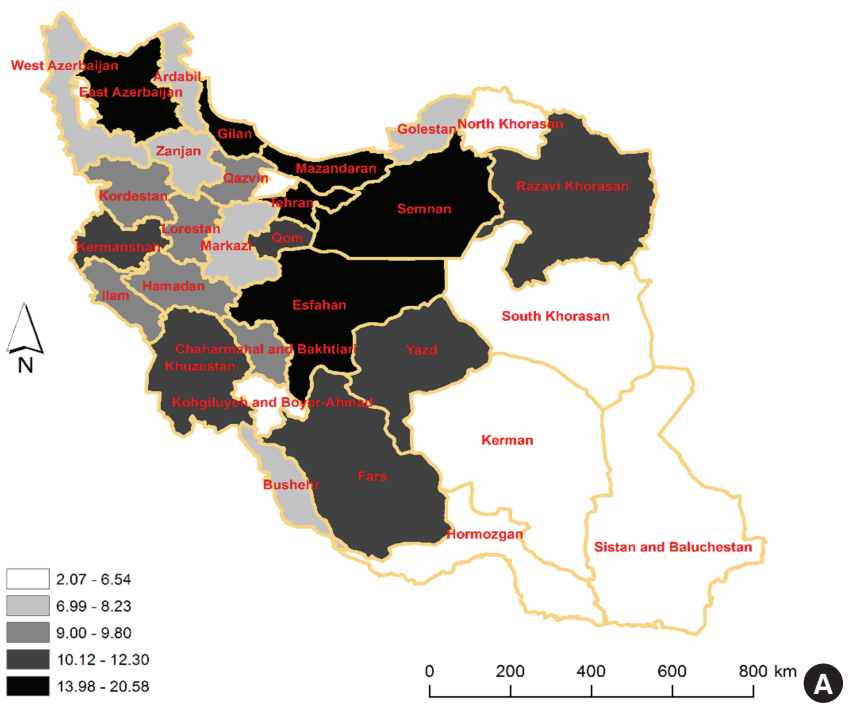

and the Center for Disease Control and Prevention of the Ministry of Health and Medical Education of Iran [11]. Patient data were originally collected by the Iranian Cancer Registry, which collects only pathology-based records from pathological laboratories across the country. Hospital-based and death certificate-based data were not included.

Data collected through the Iranian Cancer Registry were transmitted to the Iranian Ministry of Health every 3-month after repeated records had been removed. The registered data were then classified into 3 parts: part I included patient characteristics, such as age, sex, race, and place of residence; part II included the clinical history of the patient; and part III included preclinical findings. Data on the primary location of the tumor, diagnosis, morphology, cancer histology and behavior, and diagnostic method were registered accordingly.

In part I, the name of the physician who performed the biopsy, the name of the hospital where the biopsy occurred, the location from which the biopsy was taken, the clinical diagnosis, and the date the biopsy was sent to the histology laboratory were included, in addition to general patient characteristics, such as demographic information such as race and place of residence. In part II, the most important findings from patients' clinical records were included. In part III, preclinical findings were included. Physicians filled out the clinical data form while the official personnel recorded personal and demographic information in accordance with the International Classification of Diseases for Oncology (ICD-OC; topography with ICD-OM: morphology). Data were collected manually and analyzed by age and sex.

\section{Statistical analysis}

For each province, the average annual age-standardized rate (ASR) per 100,000 person-years was calculated for the incidence of CRC using the World Health Organization world standard pop-

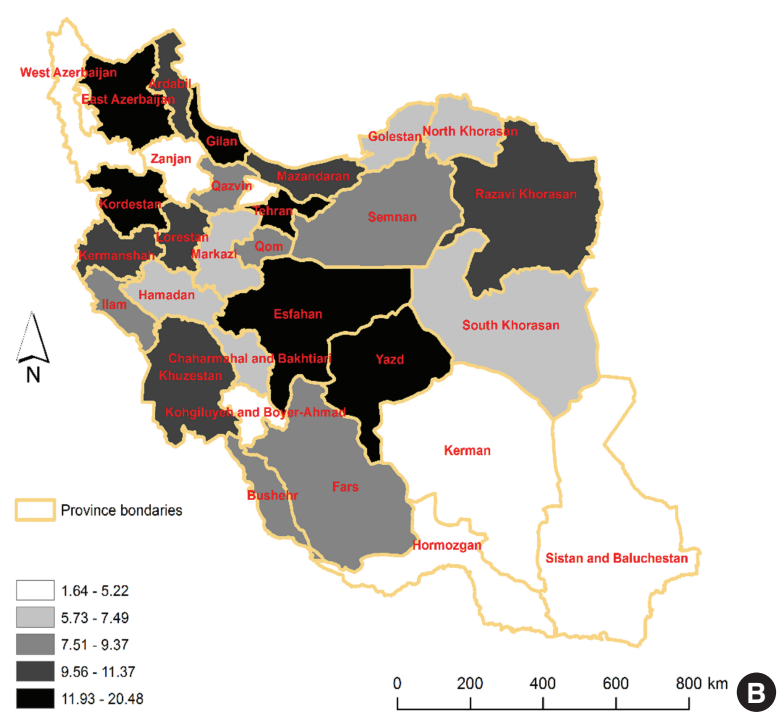

Figure 1. The geographic distribution of the age-standardized rate of colorectal cancer incidence in Iran, by sex (A: male, B: female). 
ulation [11]. The data were analyzed using MS Excel 2010 (Microsoft Corp., Redmond, WA, USA). ArcGIS 10.4.1 (ESRI, Redlands, CA, USA) was used for mapping the incidence of CRC per province.

\section{RESULTS}

Overall, 6,185 cases of CRC were registered in 2008. An assessment of the geographic distribution of these cases showed that the highest CRC incidence rates in Iran were in central, northern, and western provinces, respectively. In the central provinces of Tehran and Semnan, the ASRs of CRC incidence were 20.58 and 18.91 per 100,000 person-years, respectively. The southeast provinces of Iran had the lowest incidence rates of CRC (Figure 1).

The results of this study showed that adenocarcinoma (not otherwise specified) was the most common subtype of CRC in both sexes, accounting for $81.91 \%$ of CRC cases in males and $81.95 \%$ of CRC cases in females. Signet ring cell carcinoma was the least common subtype of CRC in males and females, accounting for 1.50 and $0.94 \%$ of CRC cases, respectively (Table 1 ).

Figure 2 shows the age-specific and sex-specific incidence of CRC. The asymmetric shape of the pyramid indicates that the incidence of CRC was higher in those who were aged 45 years or older. The highest ASRs of CRC incidence in both sexes were in the age group of $80-84$ years, with 144.69 per 100,000 personyears and 119.18 per 100,000 person-years in males and females, respectively.

The frequency, ASR, crude rate, and rank of CRC among other cancers for each province are shown in Table 2 and are stratified by sex. For Iranian males, Tehran had the highest ASR of CRC incidence, with 20.58 per 100,000 person-years, and Sistan and Baluchestan had the lowest ASR of CRC incidence, with 2.07 per 100,000 person-years. In addition, Gilan and Sistan and Baluchestan had the highest ASRs of CRC incidence among Iranian females, with 20.48 and 1.64 per 100,000 person-years, respectively. CRC was also among the 10 most common cancers among

Table 1. Morphological subtypes of colorectal cancer in 2008, by sex

\begin{tabular}{lccccc}
\hline & $\begin{array}{c}\text { Adenocarcinoma } \\
\text { NOS }\end{array}$ & $\begin{array}{c}\text { Neoplasm, } \\
\text { malignant }\end{array}$ & $\begin{array}{c}\text { Mucinous } \\
\text { adenocarcinoma }\end{array}$ & $\begin{array}{c}\text { Mucin-producing } \\
\text { adenocarcinoma }\end{array}$ & $\begin{array}{c}\text { Signet ring cell } \\
\text { carcinoma }\end{array}$ \\
\hline Male & $1,794(81.91)$ & $84(3.83)$ & $97(4.42)$ & $60(2.73)$ & $33(1.50)$ \\
Female & $1,381(81.95)$ & $75(4.45)$ & $74(4.39)$ & $49(2.94)$ & $16(0.94)$ \\
\hline
\end{tabular}

Vales are presented as number (\%).

NOS, not otherwise specified.

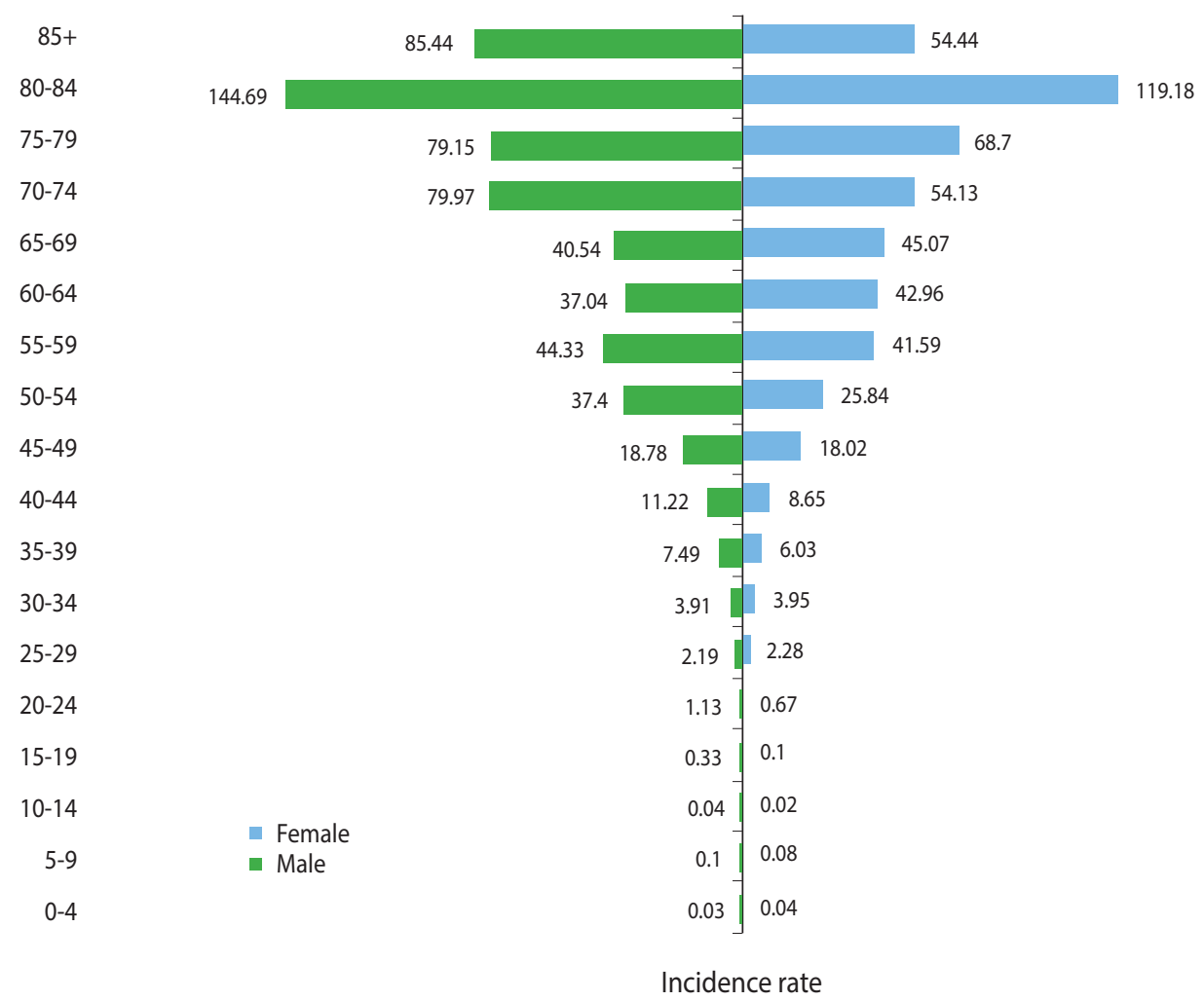

Figure 2. Age-standardized rates of colorectal cancer incidence in 2008, by age group and sex. 
Table 2. Colorectal cancer statistics according to sex and province

\begin{tabular}{|c|c|c|c|c|c|c|c|c|c|c|c|}
\hline \multirow{2}{*}{ Province } & \multicolumn{4}{|c|}{ Male } & \multirow{2}{*}{ Rank } & \multicolumn{4}{|c|}{ Female } & \multirow{2}{*}{ Rank } & \multirow{2}{*}{$\begin{array}{c}\text { Population of } \\
\text { province }\end{array}$} \\
\hline & Fre & $C R$ & ASR & $\%$ & & Fre & $C R$ & ASR & $\%$ & & \\
\hline East Azerbaijan & 216 & 11.70 & 14.97 & 8.46 & 4 & 163 & 9.30 & 13.32 & 8.18 & 4 & $3,724,620$ \\
\hline Fars & 178 & 8.11 & 10.47 & 7.40 & 6 & 124 & 5.95 & 8.61 & 6.28 & 3 & $4,596,658$ \\
\hline Razavi Khorasan & 265 & 9.01 & 11.82 & 7.57 & 5 & 216 & 7.74 & 11.37 & 7.75 & 4 & $5,994,402$ \\
\hline Esfahan & 248 & 10.51 & 13.98 & 9.38 & 3 & 184 & 8.22 & 11.93 & 8.39 & 3 & $5,779,312$ \\
\hline Gilan & 153 & 12.54 & 16.35 & 10.92 & 4 & 163 & 14.08 & 20.48 & 15.75 & 2 & $2,480,874$ \\
\hline Kermanshah & 86 & 8.96 & 11.55 & 8.41 & 4 & 77 & 8.46 & 11.26 & 9.41 & 3 & $1,945,227$ \\
\hline West Azerbaijan & 82 & 5.61 & 7.37 & 6.78 & 5 & 47 & 3.39 & 5.22 & 5.38 & 6 & $3,080,576$ \\
\hline Semnan & 43 & 14.25 & 18.91 & 8.96 & 3 & 17 & 5.94 & 9.37 & 4.51 & 6 & 631,218 \\
\hline Kordestan & 60 & 8.11 & 9.80 & 6.05 & 7 & 57 & 8.12 & 12.67 & 7.95 & 5 & $1,493,645$ \\
\hline Yazd & 49 & 9.66 & 12.30 & 7.57 & 5 & 51 & 10.60 & 14.96 & 8.84 & 4 & $1,074,428$ \\
\hline Chaharmahal \& Bakhtiari & 33 & 7.52 & 9.00 & 8.38 & 5 & 17 & 4.08 & 6.09 & 6.16 & 6 & 895,263 \\
\hline Hamadan & 63 & 7.24 & 9.66 & 5.90 & 6 & 35 & 4.24 & 5.84 & 5.23 & 5 & $1,758,268$ \\
\hline Qazvin & 40 & 6.89 & 9.36 & 7.50 & 4 & 35 & 6.35 & 9.11 & 8.14 & 3 & $1,201,565$ \\
\hline Zanjan & 30 & 6.11 & 6.99 & 7.79 & 4 & 12 & 2.58 & 3.46 & 4.84 & 5 & $1,015,734$ \\
\hline Ilam & 18 & 6.45 & 9.20 & 8.49 & 5 & 17 & 6.42 & 9.14 & 11.56 & 4 & 557,599 \\
\hline Kohgiluyeh \& Boyer-Ahmad & 15 & 4.63 & 6.54 & 5.81 & 6 & 10 & 3.25 & 4.45 & 5.62 & 6 & 658,629 \\
\hline Mazandaran & 163 & 10.96 & 14.46 & 9.16 & 4 & 111 & 7.86 & 11.07 & 7.46 & 4 & $3,073,943$ \\
\hline Tehran & 1,096 & 16.03 & 20.58 & 10.46 & 5 & 774 & 11.93 & 16.84 & 8.95 & 3 & $12,183,391$ \\
\hline Lorestan & 61 & 7.01 & 9.48 & 6.30 & 6 & 54 & 6.54 & 9.56 & 7.62 & 5 & $1,754,243$ \\
\hline Khuzestan & 192 & 8.82 & 11.65 & 7.19 & 7 & 145 & 7.02 & 10.02 & 6.03 & 3 & $4,531,720$ \\
\hline Markazi & 43 & 6.19 & 8.23 & 7.49 & 5 & 33 & 5.01 & 6.93 & 8.55 & 3 & $1,413,959$ \\
\hline Golestan & 49 & 5.93 & 7.97 & 7.90 & 5 & 41 & 5.23 & 7.49 & 8.06 & 3 & $1,777,014$ \\
\hline Qom & 42 & 7.85 & 10.12 & 10.24 & 3 & 32 & 6.31 & 8.86 & 9.47 & 3 & $1,151,672$ \\
\hline Ardabil & 41 & 6.53 & 8.08 & 5.99 & 6 & 38 & 6.37 & 9.81 & 8.54 & 4 & $1,248,488$ \\
\hline Kerman & 59 & 4.41 & 5.69 & 5.51 & 7 & 44 & 3.47 & 4.83 & 5.17 & 5 & $2,938,988$ \\
\hline North Khorasan & 13 & 3.13 & 3.75 & 4.35 & 7 & 18 & 4.54 & 6.28 & 7.23 & 4 & 867,727 \\
\hline Bushehr & 24 & 5.21 & 7.33 & 8.39 & 4 & 24 & 5.50 & 7.51 & 8.76 & 3 & $1,032,949$ \\
\hline Hormozgan & 34 & 4.86 & 5.78 & 11.30 & 1 & 22 & 3.32 & 4.21 & 7.28 & 2 & $1,578,183$ \\
\hline Sistan \& Baluchestan & 20 & 1.63 & 2.07 & 5.85 & 5 & 14 & 1.20 & 1.64 & 4.50 & 7 & $2,534,327$ \\
\hline South Khorasan & 7 & 2.44 & 3.06 & 3.61 & 10 & 11 & 4.05 & 5.73 & 5.91 & 6 & 662,534 \\
\hline Total & 3,527 & 9.80 & 12.70 & 8.34 & 5 & 2,658 & 7.78 & 11.12 & 7.85 & 3 & $73,637,156$ \\
\hline
\end{tabular}

Fre, frequency; $C R$, crude rate; $A S R$, age-standardized rate.

males and females in all provinces of Iran, and was the fourth most common cancer in males and the third most common cancer in females (Table 2).

\section{DISCUSSION}

The highest incidence rates of CRC in Iran were found in the central, northern, and western provinces. The southwest provinces of Iran had the lowest incidence rates of CRC in the country. The incidence of CRC was higher in males than in females and increased with age. However, within the age groups of 60-64 years and 65-69 years, the incidence rates for females were higher than the incidence rates for males, and in males aged 70 years or older, the incidence of CRC was the highest. Additionally, adenocarcinoma (not otherwise specified) was the most common subtype of $\mathrm{CRC}$ in both sexes.
Variations in CRC incidence rates were observed after adjusting for age across different provinces in the country. The highest incidence of CRC occurred in provinces located around central and northern Iran. Some studies found that incidence rates of CRC were not uniformly distributed across different geographic areas [12-14]. Other reports also found that the ASR of CRC incidence in southern Iran was lower than the ASR in northern Iran $[1,15,16]$, which is consistent with our results. In different studies, several aspects of the variation in incidence rates were investigated.

The role of socioeconomic status (SES) must be considered. The association between SES and the incidence of CRC differs across the globe [17]. Some studies reported that people living in low income areas had lower incidence rates of CRC than those living in higher income areas and that SES was significantly associated with CRC incidence $[13,18]$. On the contrary, individuals with lower SES were found to have a higher incidence of CRC in North Amer- 
ica [19] and Canada [20].

There are several mechanisms through which the incidence of CRC might differ across geographic areas. Firstly, changes in lifestyle and differences in exposure to risk factors are the consequence of SES over time. Diet, obesity, and physical inactivity, as lifestyle characteristics, might play crucial roles in the etiology of CRC [21]. According to a previous estimation, almost $45 \%$ of all cases of CRC in high-risk populations could be attributed to these risk factors [22].

Secondly, high SES has been found to be related to high screening participation, which may lead to an increase in the incidence of CRC due to early detection of the disease [23]. However, high levels of screening may result in a decrease in the incidence of CRC if they lead to a rise in the removal of tumors at a precancerous stage [24]. Furthermore, disparities in access to health services and therapeutic interventions may be associated with SES and, subsequently, geographic variation in the disease [25].

Lastly, an increase in the incidence of CRC has been reported in industrial regions that have high concentrations of carcinogens in the air, water, and soil [26].

Our findings are consistent with the current literature. Iran's population consists of various ethnic groups and cultural systems that vary by region. Regions with higher standards of living and better SES were found to have higher incidence rates. These areas were also more industrial than others. Furthermore, the prevalence of risk factors related to CRC was found to be higher in these regions.

Previous studies have emphasized the importance of geographical factors on CRC. Some studies have found an association between vitamin D deficiency and the incidence of CRC [22,27,28], with vitamin D levels varying by region. Subsequently, regions with low sunlight intensity have been found to have a high incidence of CRC. Our study corroborates these findings, as the lowest ASRs for CRC incidence were found in the southern provinces of the country that are closer to the equator.

We found that the ASR of CRC incidence in males was higher than in females, with a male-to-female ratio of 1.14:1. In China, this ratio was found to be 1.42:1 [4], and in Malaysia, this ratio was found to be 1.33:1 [16]. The male-to-female incidence ratio in the US was found to be 1.1 for patients aged 49 years or younger, 1.4 for patients aged 50-79 years, and 1.2 for patients aged 80 or older [7]. Studies have shown that the incidence of CRC in females may be reduced by hormone replacement therapy through the effect of female sex hormones on cholesterol metabolism, which may subsequently affect bile acid production. This pathway has been associated with the development of CRC [10].

We found that the incidence of CRC increased with age, particularly after the age of 50. It has been reported that CRC is not common among individuals aged 40 years or younger [29] and that incidence increases after the age of 40 , and more sharply, after the age of 50 [2]. This is consistent with our findings.

The relationship between age and CRC is yet to be understood [30]. This may be due primarily to the time-dependent accumula- tion of risk factors that leads to genetic and epigenetic mutations [31]. The disruption of DNA repair mechanisms and cell growth regulation systems, increased inflammation, and decreased immune system function occur with aging and may lead to genetic mutations. Our results, however, suggest that the optimal age for screening is 50 years old.

In Iran, the most common subtype of CRC was found to be adenocarcinoma (not otherwise specified). Studies conducted in China [32] and Jamaica [33] found similar results.

One important strength of our study was the use of routine data from the Iranian Cancer Registry, which covered $86.7 \%$ of the population. There were, however, some limitations to our research. We had little access to data on cancer staging at the time of diagnosis, which limited our ability to conduct a more detailed investigation. However, this limitation did not have any effect on the results of our data on the provincial level.

In conclusion, wide geographical variation was found in the incidence of CRC across the 31 provinces of Iran. These variations must be considered for prevention and control programs for CRC, as well as for resource allocation purposes.

\section{ACKNOWLEDGEMENTS}

The authors would like to thank the National Cancer Department staff at the Ministry of Health and Medical Education for providing data for the research of cancer epidemiology in Iran.

\section{CONFLICT OF INTEREST}

The authors have no conflicts of interest to declare for this study.

\section{ORCID}

Fatemeh Khosravi Shadmani: http://orcid.org/0000-0002-51727950; Kamyar Mansori: https:/0000-0001-5008-8547

\section{REFERENCES}

1. Torre LA, Bray F, Siegel RL, Ferlay J, Lortet-Tieulent J, Jemal A. Global cancer statistics, 2012. CA Cancer J Clin 2015;65:87-108.

2. International Agency for Research on Cancer. GLOBOCAN 2008: cancer incidence and mortality worldwide; 2010 [cited 2012 Jul 12]. Available from: https://www.iarc.fr/en/media-centre/ iarcnews/ 2010/globocan2008.php.

3. Ferlay J, Soerjomataram I, Dikshit R, Eser S, Mathers C, Rebelo M, et al. Cancer incidence and mortality worldwide: sources, methods and major patterns in GLOBOCAN 2012. Int J Cancer 2015; 136:E359-E386.

4. Huxley RR, Ansary-Moghaddam A, Clifton P, Czernichow S, Parr CL, Woodward M. The impact of dietary and lifestyle risk factors on risk of colorectal cancer: a quantitative overview of the epidemiological evidence. Int J Cancer 2009;125:171-180.

5. Jemal A, Center MM, DeSantis C, Ward EM. Global patterns of 
cancer incidence and mortality rates and trends. Cancer Epidemiol Biomarkers Prev 2010;19:1893-1907.

6. Cheung DY, Kim TH, Kim CW, Kim JI, Cho SH, Park SH, et al. The anatomical distribution of colorectal cancer in Korea: evaluation of the incidence of proximal and distal lesions and synchronous adenomas. Intern Med 2008;47:1649-1654.

7. Mohagheghi MA, Mosavi-Jarrahi A, Malekzadeh R, Parkin M. Cancer incidence in Tehran metropolis: the first report from the Tehran Population-based Cancer Registry, 1998-2001. Arch Iran Med 2009;12:15-23.

8. Mahmoudlou A, Yavari P, Abolhasani F, Khosravi A, Ramazani R. Estimation of the attributable burden of colorectal cancer in Iran in 2008. Iran J Epidemiol 2014;9:1-9 (Persian).

9. Johnson CM, Wei C, Ensor JE, Smolenski DJ, Amos CI, Levin B, et al. Meta-analyses of colorectal cancer risk factors. Cancer Causes Control 2013;24:1207-1222.

10. Larsson SC, Orsini N, Wolk A. Diabetes mellitus and risk of colorectal cancer: a meta-analysis. J Natl Cancer Inst 2005;97:16791687.

11. Boyle P, Parkin DM. Cancer registration: principles and methods. Statistical methods for registries. IARC Sci Publ 1991:126-158.

12. Boyle P, Leon ME. Epidemiology of colorectal cancer. Br Med Bull 2002;64:1-25.

13. Torabi M, Green C, Nugent Z, Mahmud S, Demers A, Griffith J, et al. Geographical variation and factors associated with colorectal cancer mortality in a universal health care system. Can J Gastroenterol Hepatol 2014;28:191-197.

14. Lai SM, Zhang KB, Uhler RJ, Harrison JN, Clutter GG, Williams MA. Geographic variation in the incidence of colorectal cancer in the United States, 1998-2001. Cancer 2006;107:1172-1180.

15. Haghdoost AA, Chamani G, Zarei MR, Rad M, Heshmatpoor M, Marzban M. Low incidence of colorectal cancer in Kerman province, Iran. Iran J Cancer Prev 2011;4:33-37.

16. Abu Hassan MR, Ismail I, Mohd Suan MA, Ahmad F, Wan Khazim WK, Othman Z, et al. Incidence and mortality rates of colorectal cancer in Malaysia. Epidemiol Health 2016;38:e2016007.

17. Yu XQ, O'connell DL, Gibberd RW, Armstrong BK. A populationbased study from New South Wales, Australia 1996-2001: area variation in survival from colorectal cancer. Eur J Cancer 2005;41: 2715-2721.

18. Brooke HL, Talbäck M, Martling A, Feychting M, Ljung R. Socioeconomic position and incidence of colorectal cancer in the Swedish population. Cancer Epidemiol 2016;40:188-195.

19. Aarts MJ, Lemmens VE, Louwman MW, Kunst AE, Coebergh JW. Socioeconomic status and changing inequalities in colorectal cancer? A review of the associations with risk, treatment and outcome. Eur J Cancer 2010;46:2681-2695.

20. Mackillop WJ, Zhang-Salomons J, Boyd CJ, Groome PA. Associations between community income and cancer incidence in Canada and the United States. Cancer 2000;89:901-912.
21. Wiseman M. The second World Cancer Research Fund/American Institute for Cancer Research expert report. Food, nutrition, physical activity, and the prevention of cancer: a global perspective. Proc Nutr Soc 2008;67:253-256.

22. Ono Y, Suzuki A, Kotake M, Zhang X, Nishiwaki-Yasuda K, Ishiwata $\mathrm{Y}$, et al. Seasonal changes of serum 25 -hydroxyvitamin $\mathrm{D}$ and intact parathyroid hormone levels in a normal Japanese population. J Bone Miner Metab 2005;23:147-151.

23. Centers for Disease Control and Prevention (CDC). Increased use of colorectal cancer tests--United States, 2002 and 2004. MMWR Morb Mortal Wkly Rep 2006;55:308-311.

24. Menvielle G, Leclerc A, Chastang JF, Melchior M, Luce D; Evolution Des Inégalités Sociales Par Causes Médicales de Décès (Trend in Social Inequalities by Cause of Death) Group. Changes in socioeconomic inequalities in cancer mortality rates among French men between 1968 and 1996. Am J Public Health 2007;97:20822087.

25. Lyratzopoulos G, Sheridan GF, Michie HR, McElduff P, Hobbiss $\mathrm{JH}$. Absence of socioeconomic variation in survival from colorectal cancer in patients receiving surgical treatment in one health district: cohort study. Colorectal Dis 2004;6:512-517.

26. Kutikhin AG, Yuzhalin AE, Brailovskiy VV, Zhivotovskiy AS, Magarill YA, Brusina EB. Analysis of cancer incidence and mortality in the industrial region of South-East Siberia from 1991 through 2010. Asian Pac J Cancer Prev 2012;13:5189-5193.

27. Moan J, Porojnicu AC, Robsahm TE, Dahlback A, Juzeniene A, Tretli S, et al. Solar radiation, vitamin D and survival rate of colon cancer in Norway. J Photochem Photobiol B 2005;78:189-193.

28. Robsahm TE, Tretli S, Dahlback A, Moan J. Vitamin D3 from sunlight may improve the prognosis of breast-, colon- and prostate cancer (Norway). Cancer Causes Control 2004;15:149-158.

29. Macrae FA. Colorectal cancer: epidemiology, risk factors, and protective factors [cited 2017 May 31]. Available from: http://www. uptodate.com/contents/colorectal-cancer-epidemiology-risk-factors-and-protective-factors\#H3.

30. Sadjadi A, Zahedi MJ, Darvish Moghadam S, Nouraie M, Alimohammadian M, Ghorbani A, et al. The first population-based cancer survey in Kerman Province of Iran. Iran J Publ Health 2007; 36:26-34.

31. Sarmast Shoushtari MH, Najib Poor N, Mohammadi-Asl J. Clinical charactrisitics of colorectal cancer in Razi and Gholestan hospitals of Ahwaz (1992-1999). Jundishapur Sci Med J 2002:50-55 (Persian).

32. Xu AG, Jiang B, Zhong XH, Liu JH. Clinical epidemiological characteristics of 3870 cases of colorectal cancers in Guangdong region. Zhonghua Nei Ke Za Zhi 2006;45:9-12 (Chinese).

33. McFarlane ME, Rhoden A, Fletcher PR, Carpenter R. Cancer of the colon and rectum in a Jamaican population: diagnostic implications of the changing frequency and subsite distribution. West Indian Med J 2004;53:170-173. 